\title{
STAGED COMBUSTION CONTROL FOR AVIATION ENGINES: A MULTI-OBJECTIVE OPTIMISATION APPROACH
}

\author{
SK Kim, TV Breikin, SM Hargrave, HA Thompson, \\ PJ Fleming and SJ Riley*
}

\author{
Rolls-Royce University Technology Centre, \\ Department of Automatic Control \& Systems Engineering, \\ University of Sheffield, $U K$ \\ * Controls Technology Acquisition, Rolls-Royce plc, Derby, UK
}

\begin{abstract}
This paper focuses on multi-objective optimisation of staged combustion control for aviation gas turbine engines. Pareto optimisation based multi-objective genetic algorithms are used to design the fuel distribution control laws of a staged combustor. The results of control system parameter optimisation over International Civil Aviation Organisation Landing and Take-off cycle and the typical engine operation condition are presented. An analysis of the control-related issues for optimal fuel distribution is presented.
\end{abstract}

Keywords: aerospace, optimisation, genetic algorithms

NOMENCLATURE

CO Carbon oxide

$\triangle, \mathrm{D} \quad$ Difference

EICO Index of $\mathrm{CO}$

EINOx Index of $\mathrm{NO}_{\mathrm{x}}$

EIUHC Index of UHC

FN Thrust

FAR Fuel-to-Air Ratio

FSPLT Fuel split ratio

ICAO International Civil Aviation Organisation

LTO Landing and Take-off

MOGA Multi-objective genetic algorithm

$\mathrm{NO}_{\mathrm{x}} \quad$ Nitrogen oxides

PI Proportional + Integral

$\mathrm{T} \quad$ Flame temperature

UHC Unburned hydro-carbonate

WF Fuel flow

WA Air flow

\section{INTRODUCTION}

The development of low emission gas turbine engines for civil aerospace is critical with the projected increases in air traffic over the next couple of decades. ICAO (International Civil Aviation Organisation) sets emission control requirements for civil aircraft. Limits were originally set in terms of pollutants produced per unit thrust or unit mass of fuel burned over the landing and take-off cycle. Tightening of the $\mathrm{NO}_{\mathrm{x}}$ standards and additional emphasis on $\mathrm{CO}$ emissions have recently been imposed and reflect the increased concern that emissions generated at altitude have on the atmosphere.

The most effective way of reducing the emissions generated by an aviation gas turbine engine is to stage the fuel combustion. A simplified scheme of a staged combustor is presented in Figure 1. Staging the combustion process results in reduction of $\mathrm{NO}_{\mathrm{x}}$ emissions whilst maintaining other pollutants at low levels. This is achieved by sharing the fuel load 
among several fuel and air stages, thus enabling the control of the local Fuel-to-Air Ratios (FAR) to minimise $\mathrm{NO}_{\mathrm{x}}$ formation rates as the power increases (Koff, 1994). Staging the combustion between primary and main zones requires the resolution of two controls-related issues. The first problem is to determine and maintain an optimal split of total fuel flow between the pilot and main burners during steady-state operation. The optimisation criteria is such that the output emissions are minimised, whilst maintaining the original design requirements in terms of safety, reliability, availability, etc. The second problem is to minimise the effect of the local FAR deviations during transient manoeuvres and consequently avoid steps in the engine power.

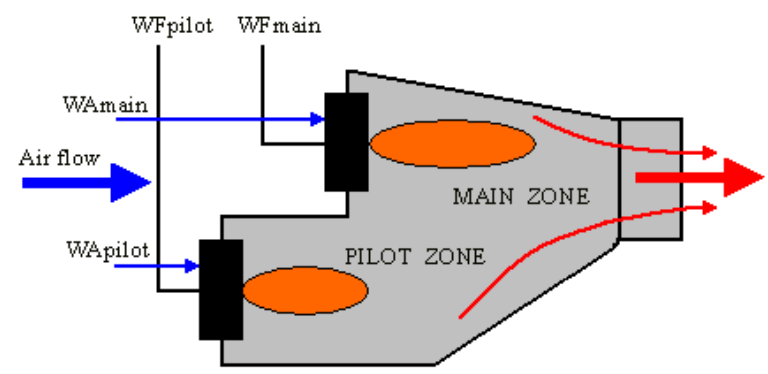

Fig. 1. Simplified scheme of a staged combustor with 2 stages.

This paper will present an analysis of the control problems associated with the staging of the fuel between the pilot and main burners of a high bypass three-shaft gas turbine engine of Trent 500 thrust class. A multi-objective optimisation approach to the design of the fuel distribution control laws is presented. Multi-objective genetic algorithms are used to tune the control system, which is Pareto optimal over the ICAO LTO cycle and typical engine operation conditions.

\section{EMISSIONS OPTIMISATION ANALYSIS}

The primary objective in the design of the fuel distribution control laws is reduction in $\mathrm{NO}_{\mathrm{x}}$ emissions. It is known (Koff, 1994; Lefebvre, 1999) that the $\mathrm{NO}_{\mathrm{x}}$ emissions rate (or $\mathrm{NO}_{\mathrm{x}}$ index) increases as an exponent function of flame temperature, whilst that of $\mathrm{CO}$ and UHC decrease. It is presumed that the flame temperature has a strong correlation with local FAR within the flame zone and consequently the $\mathrm{NO}_{\mathrm{x}}$ index can also be considered a function of FAR.

It is reasonable to assume that combustors of identical geometry will generate identical emissions under identical operating conditions. In other words, maintaining identical FAR within two combustors of similar geometry will results in identical $\mathrm{NO}_{\mathrm{x}}$ emissions. Manufacturing deviations between combustors are considered to have a negligible influence on $\mathrm{NO}_{\mathrm{x}}$ generation and are therefore ignored.

It is straightforward to deduce that the total $\mathrm{NO}_{\mathrm{x}}$ generated within two combustors of identical geometry is minimised when the FAR within the two combustion zones are equal. Furthermore, by assuming that the airflow rates through the two combustors are identical, which is not unreasonable for combustion chambers of identical geometry, then the total $\mathrm{NO}_{\mathrm{x}}$ emissions are minimised when the fuel flow rates to the two zones are equal.

It is reassuring to note that the results of this optimisation analysis confirm what is sensible from a practical standpoint. To minimise $\mathrm{NO}_{\mathrm{x}}$ emissions the fuel through the main burners should be burnt equally within each combustion chamber. It is recognised that this optimisation analysis ignores practical constraints that must be placed upon it, but provides a useful basis for the future optimisation.

The geometry of the pilot and main combustion zones are dissimilar and it is possible to extend the previous emission analysis to cover this situation. The different geometry and residence time of the two combustion zones will result in dissimilar emission characteristics even under identical operating conditions. Thus, even for identical FAR, which it is assumed will generate identical flame temperatures, the two combustors would generate different $\mathrm{NO}_{\mathrm{x}}$ contributions to the overall emissions. Consequently, it is possible to assume that there is an optimal FAR difference ( $\triangle \mathrm{FAR}$ ), which brings total $\mathrm{NO}_{\mathrm{x}}$ emission to a minimum for any particular power setting.

A precise model of the $\mathrm{NO}_{\mathrm{x}}$ emission is necessary in order to determine the optimal value of $\triangle F A R$ for each operating condition of the engine.

The results obtained from a generic staged combustion engine model are illustrated in Figure 2. The results compare $\mathrm{NO}_{\mathrm{x}}$ emissions in a staged combustor, where the fuel distribution was chosen such that equal FARs were obtained in the pilot and main zones and where an optimal $\triangle F A R$ schedule was utilised. It can be seen that a quite significant reduction in $\mathrm{NO}_{\mathrm{x}}$ can be achieved by optimising the fuel distribution in a staged combustor.

However, practical issues will render the necessary assumptions in this emissions optimisation inappropriate at particular operating conditions. Consequently, issues of flame stability (which is 
likely to require combustion zones to operate towards stoichiometric), combustion rumble and weak extinction will stretch the validity of these assumptions used in the previous analysis.

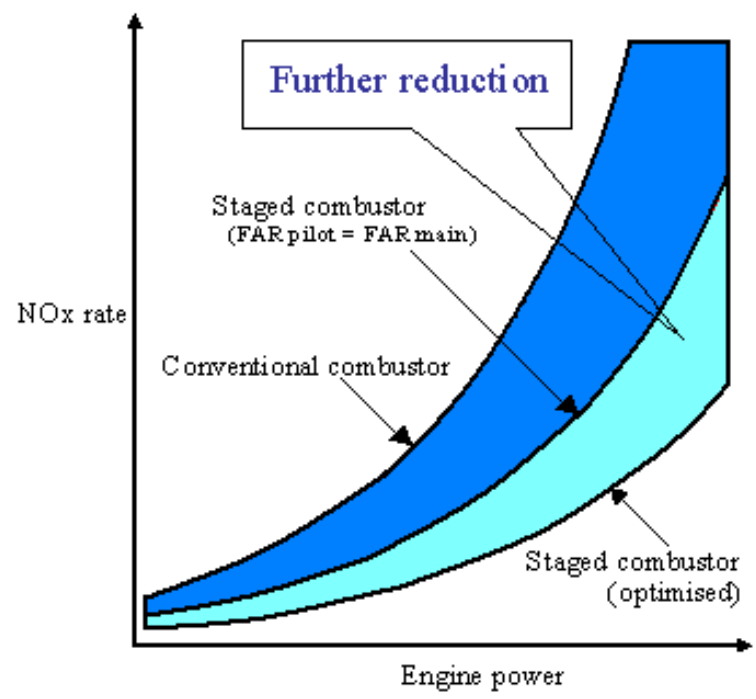

Fig. 2. $\mathrm{NO}_{\mathrm{x}}$ rate vs engine power.

The consequence of these practical constraints is that it will be necessary to operate the staged combustor under sub-optimal conditions from an emissions reduction point of view over particular power ranges. Combined with the inherent trade-off between $\mathrm{NO}_{\mathrm{x}}$ and $\mathrm{CO}$ emissions it can clearly be seen that the problem is one of a multi-objective optimisation

\section{MULTI-OBJECTIVE GENETIC ALGORITHMS}

Multi-objective optimisation recognises that a set of design criteria for most practical problems needs to be satisfied simultaneously. A multi-objective optimisation problem might be formulated as follows:

$$
\min \mathrm{F}(\mathrm{x}) \text { for } \mathrm{x} \in \Omega \text {, }
$$

where $\mathrm{x}=\left[\mathrm{x}_{1}, \mathrm{x}_{2}, \ldots, \mathrm{x}_{\mathrm{n}}\right]$, variables, $\Omega$ defines the set of variables $x$, and $F(x)=\left[f_{1}(x), f_{2}(x), \ldots, f_{n}(x)\right]$ are the design objectives to be minimised.

An evolutionary algorithm approach (multi-objective genetic algorithms MOGA) demonstrates advantages over conventional optimisation approaches with the capability of handling function discontinuity, multimodality and employing a mixture of decision variable types. Furthermore, its population-based search approach affords the opportunity to evolve a family of solutions. For multi-objective optimisation problems, there is no unique ideal optimal solution but rather a set of Pareto-optimal solutions known as a non-inferior or non-dominated solutions, for which an improvement in one of the design objectives will lead to a degradation in one or more of the remaining objectives (Fonseca \& Fleming, 1993).

\section{STEADY-STATE EMISSIONS OPTIMISATION}

The steady-state fuel split schedule optimisation over the engine operating range is a multi-objective problem. It requires finding an optimal $\triangle F A R$ between pilot and main zones, which would result in minimisation of $\mathrm{NO}_{\mathrm{x}}, \mathrm{CO}$ and UHC emissions over the ICAO LTO cycle. Furthermore, the solution should achieve low emissions during cruise, whilst simultaneously ensuring against both weak and rich extinction and incomplete combustion.

The conflicting demands on the optimisation of the fuel split, which correlate to the optimal $\triangle F A R$ in a staged combustor, for a single total fuel flow to the engine are highlighted in Figure 3.

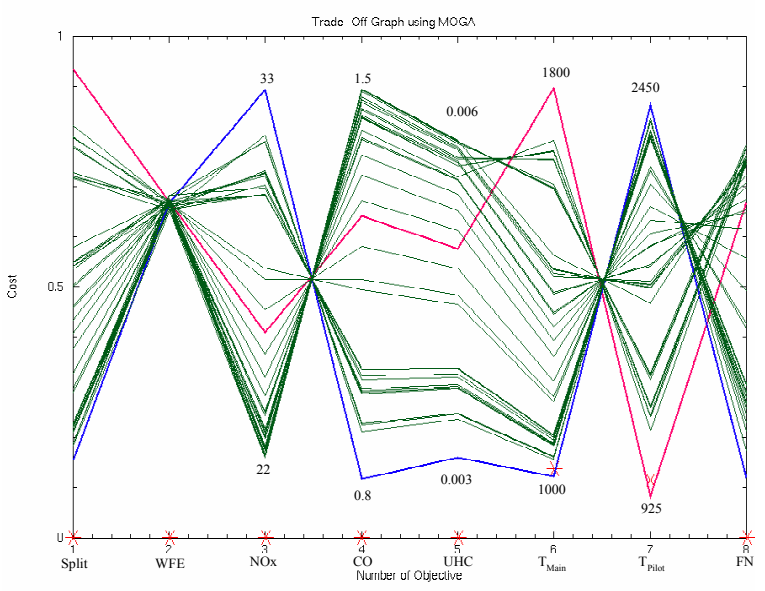

Fig. 3. Trade-off graph of fuel schedule optimisation

A family of solutions to the optimisation problem is presented in this trade-off graph. The horizontal axis represents a discrete set of design objectives and the vertical axis that of the associated costs. The key points to note from this type of graph are that crossing lines indicate a trade-off between two competing objectives and parallel lines indicate two complementary objectives. These points are illustrated in Figure 3 with the competing objectives of $\mathrm{NO}_{\mathrm{x}}$ and $\mathrm{CO}$ emissions reduction and the noncompeting objectives of $\mathrm{CO}$ and UHC emissions. This type of trade-off graph provides an approach to define the steady-state open-loop control schedule by imposing constraints on the maximum/minimum local FAR in the pilot and main zones to ensure that rich and weak extinction are avoided in the combustion zones. 


\subsection{ICAO LTO Cycle Emissions Optimisation}

The primary scheduling variable in the open-loop control scheme is that of demanded fuel flow. Essentially, the aim in the derivation of the control schedule is to maintain fixed splits between the respective fuel-to-air ratios for each operating mode of the burner banks.

The ICAO regulation levels for different kinds of emissions are shown in Table 1 for the application engine. The MOGA tool was used to find Paretooptimal values of fuel split between the pilot and main zones of combustor.

$\underline{\text { Table } 1 \text { Achieved LTO level using MOGA }}$

\begin{tabular}{|c|c|c|c|}
\hline LTO level & $\mathrm{NO}_{\mathrm{x}}$ & $\mathrm{CO}$ & UHC \\
\hline ICAO, $[\mathrm{g} / \mathrm{kN}]$ & 63 & 118 & 19.6 \\
\hline Achieved, $[\mathrm{g} / \mathrm{kN}]$ & 50.7 & 20.9 & 0.14 \\
\hline Achieved, $[\%]$ & 80.5 & 17.3 & 0.7 \\
\hline
\end{tabular}

A set of obtained Pareto-optimal solutions is presented in Figure 4. Sixteen objectives including FSPLT, LTO $\mathrm{NO}_{\mathrm{x}}, \mathrm{CO}$ and UHC levels and AFR in the main and pilot zones were used to find these optimal fuel split values.

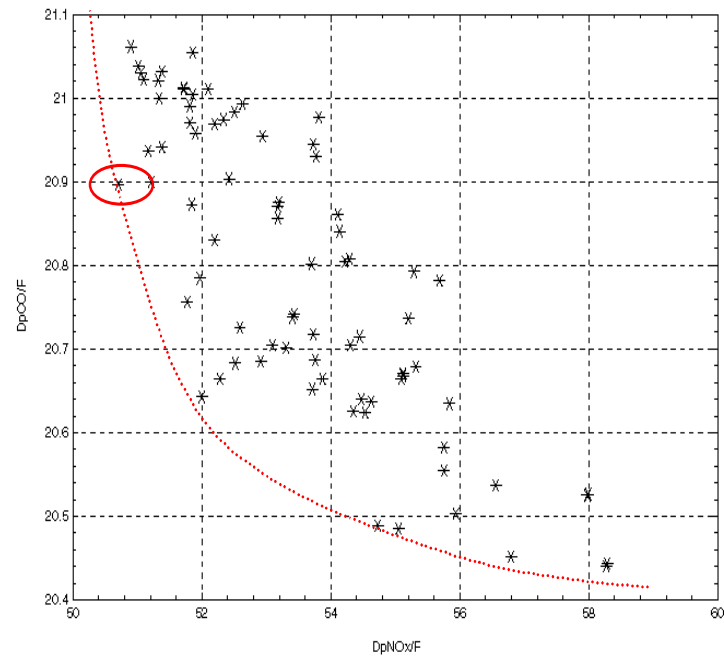

Fig. 4. Set of Pareto-optimal solutions: $\mathrm{NO}_{\mathrm{x}} \mathrm{LTO}$ level vs CO LTO level

It can be seen from Table 1 that obtained solutions satisfy the ICAO regulation levels. Furthermore, the level of $\mathrm{NO}_{\mathrm{x}}$ is more critical as it has the lowest margin with respect to the regulation limit. From this point of view a solution, which gives minimal $\mathrm{NO}_{\mathrm{x}}$ level should be selected from the obtained set of solutions illustrated in Figure 4.

Table 2 Pareto-optimal fuel split value

\begin{tabular}{|c|c|c|c|c|}
\hline LTO mode & Take-off & Climb & Approach & Idle \\
\hline FSPLT & 0.637 & 0.685 & 0.713 & 0.701 \\
\hline
\end{tabular}

A set of Pareto-optimal fuel split values for engine operating conditions defined in the LTO cycle is presented in Table 2.

\subsection{Optimisation of Typical Engine Operation}

A search of the solution space with the MOGA tool was undertaken to find fuel split values (FSPLT) that minimise $\mathrm{NO}_{\mathrm{x}}$ and $\mathrm{CO}$ emissions during cruise and descent operating conditions. Identical objectives were utilised as for LTO cycle optimisation presented earlier. The results of optimisation are presented in Figure 5, Figure 6 and Table 3.

Table 3 Pareto-optimal fuel split value for cruise and descent operations and emission indexes (g/kg fuel)

\begin{tabular}{|c|c|c|c|c|}
\hline Mode & FSPLT & EINOx & EICO & EIUHC \\
\hline Cruise & 0.651 & 17.109 & 0.5615 & 0.0091 \\
\hline Descent & 0.653 & 7.4134 & 4.8068 & 0.0386 \\
\hline
\end{tabular}

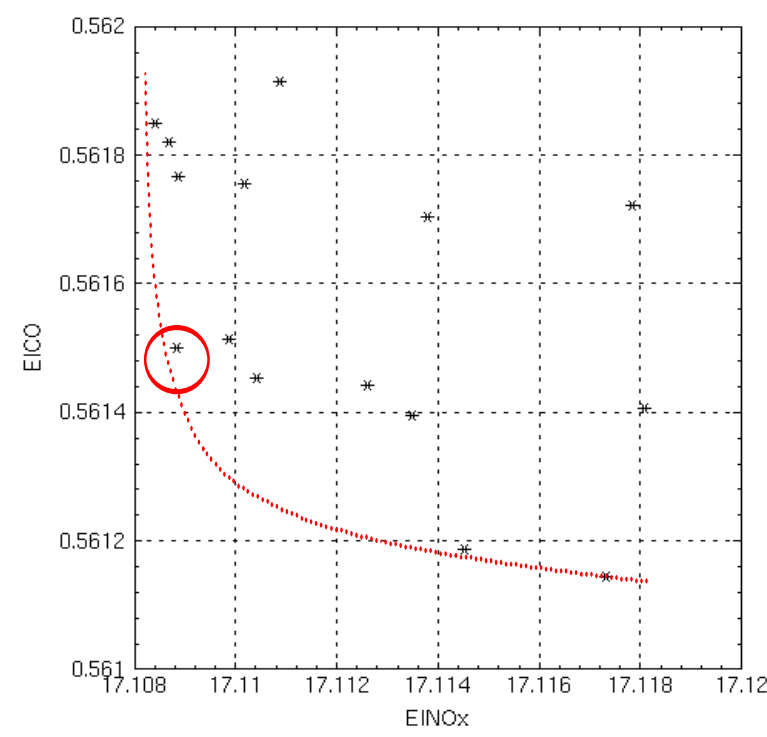

Fig. 5. Set of Pareto-optimal solutions: EINOx vs EICO for cruise operation 


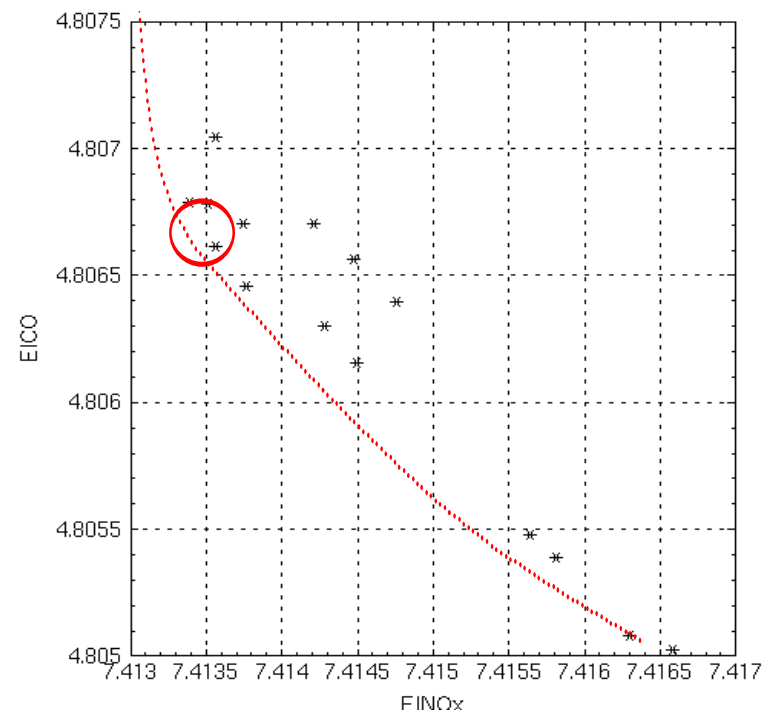

Fig. 6. Set of Pareto-optimal solutions: EINOx vs EICO for descent operation

\section{TRANSIENT OPERATION CONTROL}

One aim of the research presented in this paper is to examine the influence fuel transients have on the overall performance of the propulsion system. This includes the potential to minimise emissions during transient operations.

An initial investigation was undertaken on the preliminary model of the propulsion system to provide a general indication of the system responses and sensitivity to FAR variations. Furthermore, this preliminary model was used to highlight the advantages and drawbacks of the proposed control.

\subsection{Simulation Results of Reslam Manoeuvre}

A number of simulations of the propulsion system response to a reslam-type manoeuvre under closed-loop EPR control of the engine were undertaken. Implementation of a simple open-loop fuel schedule was employed in the distribution control of the fuel between the pilot and main burners.

The key feature to note from this reslam response is the deviations of the AFR in pilot and main zones from the steady-state operating line, which is illustrated in Figure 7. A factor in the filter design of the distribution control scheme is to minimise the impact these deviations have on transient emissions of the engine.

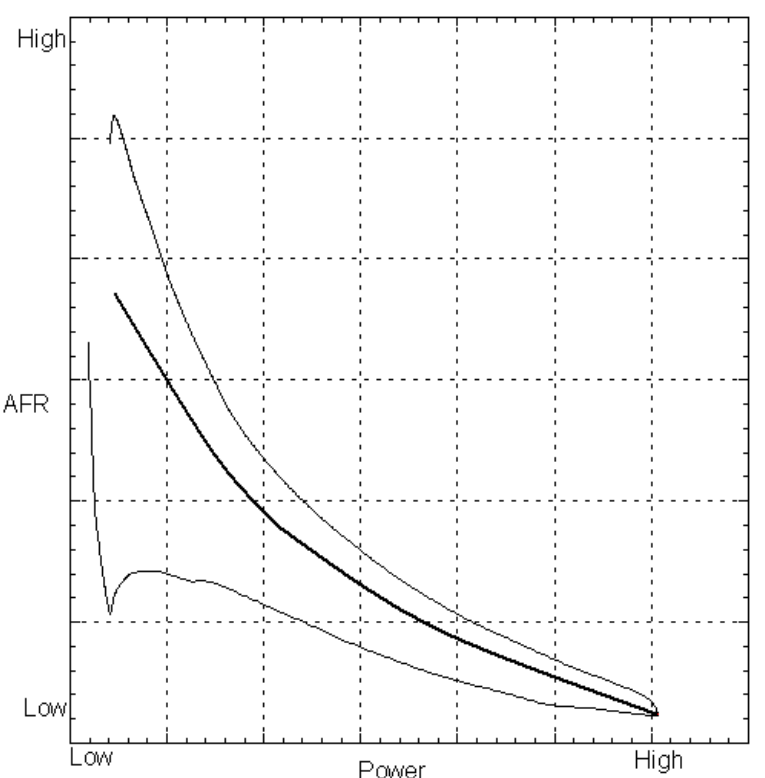

Fig. 7. Reslam Response, AFR in comparison with AFR at steady state (thick line).

\subsection{Emissions Control in Transient Operation}

A closed-loop control strategy is important when it is necessary to control transient behaviour of the system and to minimise the effect of process uncertainties on the overall performance of the system.

It is conceivable that an optimal schedule for the fuel distribution is derivable for steady-state engine operation. Consequently, a closed-loop controller that controls $\triangle F A R$ schedule to optimise the emissions reduction during transients, providing limited scope for robustness against process uncertainties and shaping of the dynamics response is a potentially attractive strategy.

The two closed-loop control configurations under consideration are based on fuel-to-air ratio and flame temperature. The favoured approach is that based on control of FAR and is illustrated in Figure 8. The primary aim of this scheme is to maintain the demanded relationship between the pilot and main fuel-to-air ratios and which is dependent upon the number of burner banks and stages selected. In this instance, the controller characteristics are specified by the two regulators, which are PI regulators. The MOGA tool was used for multi-objective tuning of these regulators. Estimation of the airflow can be achieved through the method outlined in (Corbett \& Lines, 1994). 


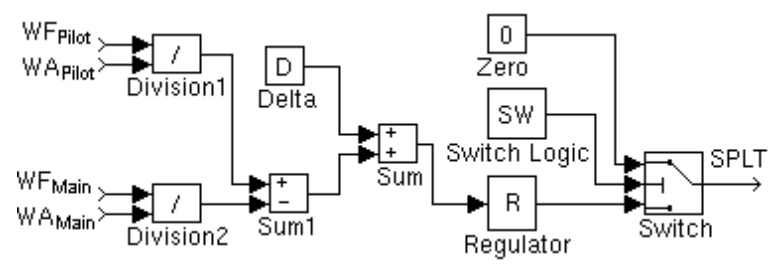

Fig. 8. Closed-Loop Control Based on FAR

The second option is to base the closed-loop control on flame temperature. A flame temperature based control scheme could be more robust than that based on FAR since it would avoid uncertainties associated with the estimation of the airflow. However, such a scheme would necessitate special sensors to measure the temperature within the combustion zone.

Simulation results, which were derived from the generic staged combustion engine model, confirmed that control designs based on these two configurations give similar $\mathrm{NO}_{\mathrm{x}}$ control results in both steady-state and transient operation.

\section{CONCLUSIONS}

A significant reduction in the overall emissions of an aviation gas turbine engine can be achieved by sharing the combustion between combustors of different geometry. In so doing, tighter control over the fuel-to-air ratio can be achieved over a wider range of engine power settings than that of a single combustor design.

The demanded fuel flow between the banks of burners within the pilot and main combustion zones should be allocated by the fuel distribution control system in order to minimise the overall engine emissions, whilst maintaining the engine within required operating constraints.

A simplified analysis of the emissions optimisation highlighted an approach to the scheduling of the control system. The approach required scheduling of the fuel according to a single $\triangle \mathrm{FAR}$ parameter, which is dependent on the engine operating condition and can be correlated to the value of fuel split between main and pilot zones of combustor. This would need to be derived from experimental data or an emissions model of the combustor behaviour.

It was shown that MOGA provides an effective tool for controller tuning in a multi-objective sense to identify preferable compromise solutions in the competing emission optimisation. Furthermore, this optimisation was achieved whilst simultaneously satisfying physical constraints of weak and rich extinction over the whole range of the engine power settings.

Simulations of the propulsion system model were undertaken to scope the impact of transfer behaviour of the engine on the emissions output. It was shown that closed-loop control on FAR or flame temperature generates good results by regulating to the optimal $\triangle F A R$ during steady-state operation and transient manoeuvres.

\section{ACKNOWLEDGEMENTS}

The authors wish to acknowledge both the financial and technical support of UK Department of Trade and Industry, TRW Aeronautical Systems and RollsRoyce in the LECCAGT project.

\section{REFERENCES}

Corbett N.C. and N.P. Lines (1994). Control Requirements for the RB211 Low Emissions Combustion System. Journal of Engineering for Gas Turbines and Power - Transactions of the ASME, 3, 527-533

Fonseca C.M. and P.J. Fleming (1993). Genetic Algorithms for Multiobjective optimisation Formulation, Discussion and Generalisation. Proc of $5^{\text {th }}$ Int. Conference on Genetic Algorithms, 416-42

Koff B.L. (1994). Aircraft Gas Turbine Emissions Challenge. Journal of Engineering for Gas Turbines and Power - Transactions of the ASME, 3, 474-477

Lefebvre L.H. (1999). Gas Turbine Combustion. Taylor \& Francis, London 